\title{
Pembentukan Kelompok Asuhan Mandiri Tanaman Obat Keluarga (TOGA) dan Akupresur di Kecamatan Sanden, Kabupaten Bantul
}

\author{
Suryani Hutomo $^{\# 1}$, Yanti Ivana Suryanto ${ }^{\# 2}$, Novika Kurniawati ${ }^{* 3}$ \\ ${ }^{\#}$ Fakultas Kedokteran,Universitas Kristen Duta Wacana \\ Jl. Dr Wahidin Sudirohusodo 5-25 Yogyakarta \\ ${ }^{1}$ suryanihutomo_drg@yahoo.com \\ 2ckivana90@gmail.com \\ *Puskesmas Sanden Bantul \\ Pucanganom, Murtigading, Sanden, Bantul, Yogyakarta \\ 3vicha2302@gmail.com
}

\begin{abstract}
In Sanden, Bantul, there were several family started managing the yard by planting medicinal plants for sale, but there was still a lot of yard was not optimally utilized. The purpose of establishing independent medicinal plants (TOGA) and acupressure groups is to increase the active participation of the community in improving their health by changing the curative paradigm to be promotive and preventive, also to improve the family economy through planting and processing TOGA grown in the yard. The activity was carried out by establishing an independent TOGA and acupressure groups in several areas managed by their own groups. In line with this activity, the Bantul Government routinely organized greenery and medicinal plants competition for each village. The goal of the competition is, besides the environment being green, the medicinal plants can help the family's economic needs.
\end{abstract}

Keywords-economic need, independent group, preventive, promotive, TOGA

\section{PENDAHULUAN}

Pembangunan kesehatan diarahkan untuk meningkatkan kesadaran, kemauan dan kemampuan hidup sehat bagi setiap orang agar dapat mewujudkan peningkatan derajat kesehatan masyarakat yang setinggi-tingginya sebagaimana ditetapkan pada Undang-Undang Nomor 17 Tahun 2007 tentang Rencana Pembangunan Jangka Panjang Nasional (RPJPN Tahun 2005 - 2025) [1]. Program Indonesia Sehat dilaksanakan dengan salah satu pilar utama yaitu paradigma sehat dilakukan dengan strategi pengarusutamaan kesehatan dalam pembangunan kesehatan, penguatan promotif, preventif dan pemberdayaan masyarakat.

Salah satu strategi pembangunan kesehatan adalah mendorong masyarakat agar mampu memelihara kesehatannya, serta mengatasi gangguan kesehatan ringan secara mandiri melalui kemampuan asuhan mandiri. Kelompok Asuhan Mandiri adalah kumpulan dari keluarga (5-10 keluarga) dengan 1 orang kader sebagai pembimbing untuk mewujudkan perubahan paradigma sakit menjadi paradigma sehat, yang bermanfaat untuk memberikan efektivitas, efisiensi dalam menjaga kesehatan diri sendiri dan keluarga sehingga terwujud keluarga sehat secara mandiri. 
Arah kebijakan kesehatan yang memperkuat upaya peningkatan kesehatan dan pencegahan penyakit serta pemberdayaan masyarakat dapat dipenuhi salah satunya oleh pelayanan kesehatan tradisional yang berorientasi pada upaya menyehatkan yang sakit dan mempertahankan yang sehat sekaligus meningkatkan kualitas hidup seseorang. Sejalan dengan Peraturan Pemerintah Nomor 103 tahun 2014 tentang Pelayanan Kesehatan Tradisional pada pasal 70 menyatakan bahwa masyarakat dapat melakukan perawatan kesehatan secara mandiri dan benar dengan memanfaatkan Taman Obat Keluarga (TOGA) dan Akupresur [2].

Tanaman obat sudah dikenal sejak lama sebagai bahan-bahan untuk pengobatan tradisional. Indonesia terkenal sebagai negara yang memiliki berbagai jenis tanaman obat. Pengobatan menggunakan tanaman obat diwariskan sebagai kekayaan budaya turun-temurun secara lisan [3].

Akupresur merupakan terapi pemijatan dengan memberikan penekanan pada titik tertentu pada tubuh yang didasarkan pada prinsip titik-titik akupunktur [4]. Tujuan penekanan pada titik-titik ini adalah untuk melancarkan berbagai sistem pada seluruh bagian tubuh. Pemijatan menggunakan ujung jari tangan pada titik tertentu di permukaan kulit ini juga dapat berdampak positif terhadap kondisi fisik, mental dan sosial [5]. Akupresur mandiri dapat dilakukan oleh masyarakat di lingkungan keluarga sendiri untuk meningkatkan kebugaran maupun mengatasi gangguan kesehatan ringan.

Pelayanan kesehatan tradisional yang merupakan upaya pengembangan di Puskesmas memanfaatkan keterlibatan masyarakat untuk memelihara kesehatannya secara mandiri. Puskesmas Sanden telah bekerjasama dengan FakultasKedokteran Universitas Kristen Duta Wacana (FK UKDW) membentuk 10 kelompok asuhan mandiri dengan memanfaatkan Taman Obat Keluarga (TOGA) dan Akupresur di wilayah Kecamatan Sanden. Tujuan dibentuknya kelompok ini adalah supaya masyarakat dapat mencegah penyakit dan melakukan pertolongan pertama ketika sakit dengan memanfaatkan TOGA. Adapun pembinaan kelompok-kelompok ini dilakukan bersama oleh FK UKDW dan Puskesmas Sanden.

\section{METODE PELAKSANAAN}

Kegiatan diawali dengan survey yang dilakukan oleh Penanggungjawab Upaya Puskesmasuntuk menjajagi minat masyarakat terhadap TOGA dan akupresur. Didapatkan bahwa sudah ada beberapa keluarga yang membudidayakan TOGA dan menjual hasil panennya langsung ke pasar atau kepada pedagang yang mendatanginya di rumah. Sebagian lagi menanam TOGA untuk dimanfaatkan sebagai bumbu dapur. Masyarakat belum mengetahui bagaimana memanfaatkan dan mengolah TOGA, serta menyatakan tertarik untuk belajar mengolah TOGA sehingga mempunyai banyak manfaat.

Observasi lapangan dilakukan oleh timFK UKDW bersama tim Puskesmas Sanden untuk menentukan lokasi kelompok Asuhan Mandiri. Dipilih empat dusun sebagai perwakilan empat desa yang ada di wilayah kecamatan Sanden, yaitu dusun Gedongan, Dayu, Piring dan Kalimundu.Dari masing-masing dusun, diajukan 5 orang warga yang akan dilatih lebih dahulu sebagai kader TOGA.Para kader ini nantinya akan membina 5-10 keluarga di wilayahnya, membentuk kelompok asuhan mandiri.

Kerangka Acuan Kegiatan disusun oleh Penanggungjawab Upaya Puskesmas bersama timFK UKDW.Pembuatan modul tentang TOGA dilakukan sebelum kegiatan pelatihan berjalan. Diharapkan modul dapat menjadi pegangan bagi para peserta pelatihan.

Kegiatan yang pertama kali dilaksanakan adalahsosialisasi rencana 
program kepada Kepala Dusun Gedongan, Dayu, Piring dan Kalimundu, serta pihak Kecamatan Sanden, para Kepala Desa. Pelaksanaan sosialisasi ini di Puskesmas Sanden. Pembinaan, monitoring dan evaluasi dilaksanakan secara bertahap. Kegiatan berlangsung dari tahun 2016 sampai dengan tahun 2018, setelah itu diharapkan masyarakat sudah mandiri.

Adapun rincian kegiatan pembentukan kelompok asuhan mandiri adalah sebagai berikut:

\section{A. Sosialisasi untuk kader dan pembagian bibit TOGA}

Kegiatan dilaksanakan pada hari Rabu16 November 2016, jam 09.00 WIB sampai selesai, bertempat di Balai Desa Murtigading. Peserta terdiri dari 20 orang kader dari 4 dusun, petugas puskesmas pendamping dusun (Gasbinsun) dan Ibu Dukuh.Materi yang disampaikan adalah Pengenalan dan Pemanfaatan Tanaman Obat, disampaikan oleh dr. Ivana. Materi ini menjelaskan tentangpengertian Tanaman Obat Keluarga (TOGA), petunjuk umum dan contoh-contoh ramuan. Para kader sangat tertarik dengan ramuan sederhana yang dapat disiapkan sendiri, tetapi mempunyai khasiat menyembuhkan penyakit.

Contoh ramuan untuk demam:

2 jari kunyit, kupas, potong-potong $+1 / 4$ genggam meniran $+1 / 2$ genggam pegagan, rebus dengan 3 gelas air hingga menyusut setengahnya, angkat, dinginkan tambah gula merah atau madu secukupnya. Untuk bayi yang berumur kurang dari 1tahun aturan minumnya adalah 1 sendok makan sebanyak 4 kali sehari, untuk balita 3 sendok makan 4x kali sehari, anak-anak 57 tahun sebanyak 6 sendok makan 4 kali sehari [6].

Materi kedua adalah Cara Penanaman dan Pengelolaan Tanaman Obat, disampaikan oleh bapak Herman.Faktor-faktor yang berpengaruh pada penanaman TOGA adalah kondisi tanah, cuaca, kebutuhan air dan pupuk. Dijelaskan pula tentang cara pembibitan dan teknik penanaman.

Sebagai contoh adalah cara menanam jahe Jahe bisa tumbuh pada ketinggian 300 sampai dengan900 $\mathrm{m}$ diatas permukaan laut. Tanaman jahe tidak boleh terkena sinar matahari secara langsung, oleh karena itu menanam jahe bisa dilakukan di kebun buah-buahan, kebun kelapa sawit atau juga di kebun pepohonan yang besar lainnya.Syarat tanam lainnya adalah pengairan yang juga harus diperhatikan dengan sangat baik. $\mathrm{pH}$ tanah harus mencukupi, yaitu antara 6,8-7,4. Memilih benih jahe yang bagus dengan ciri memiliki bakal tunas 2-3 tunas. Penyemaian bibit jahe dilakukan pada hamparan jerami atau alang alang. Sebaiknya jangan terlalu sering menyiram jahe, karena dikhawatirkan akan membuat benih jahe membusuk. Penutupan benih dengan tanah pada saat menanam juga jangan terlalu tebal dan jangan terlalu padat, agar tunas jahe bisa tumbuh dengan cepat dan sempurna [7].

Pembagian sampel bibit TOGA dilaksanakan pada akhir acara hari tersebut. Jenis bibit TOGA yang dibagikan adalah jahe, jahe merah, kunyit, kunir putih, sunthi dan kencur. Masing-masing kader membagikan bibit ini kepada 5 (lima) keluarga yang mereka dampingi untuk ditanam di halaman rumah masing-masing.

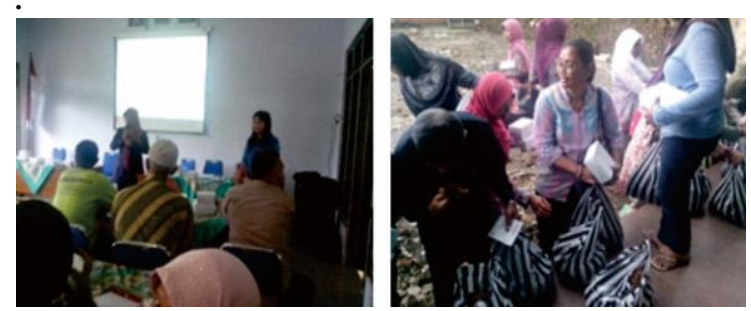

Gambar 1. Suasana pelatihan dan pembagian bibit TOGA

Monitoring pertama dilaksanakan pada tanggal 6 Desember 2016. Bibit TOGA sudah ditanam dengan benar, tetapi di beberapa tempat sempat terkendala tumbuh karena hanyut terbawa hujan yang cukup deras selama beberapa hari. Penanaman 
sempat tertunda. Pada monitoring kedua, 27 Pebruari 2017, tanaman TOGA di empat dusun percontohan sudah tumbuh cukup baik, tinggi tanaman sudah mencapai sekitar $10-20 \mathrm{~cm}$.
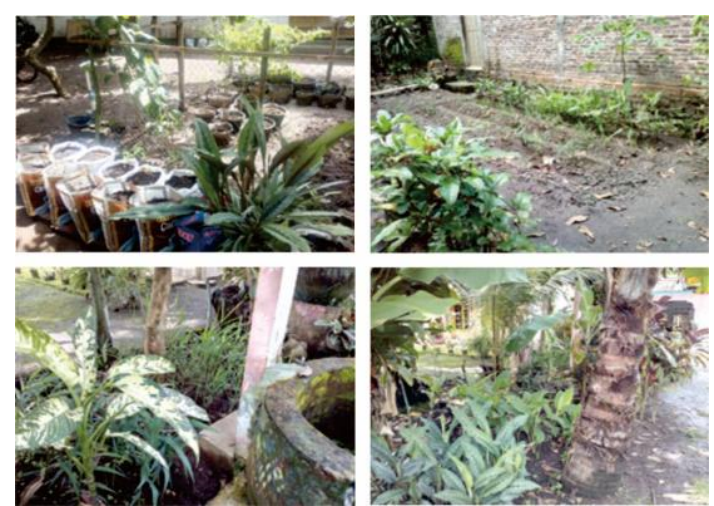

Gambar 2. Pertumbuhan TOGA pada evaluasi pertama di 4 dusun percontohan

\section{B. Pelatihan pemanfaatan TOGA dan akupresur bagi kader dan keluarga dampingan}

Pelatihan dilaksanakan pada hari Selasa dan Rabu. 9 dan 10 Mei 2017, jam 09.00-14.00 WIB.

Hari pertama terdiri dari enam materi yaitu Kebijakan TOGA di Kabupaten Bantul, asuhan mandiri pemanfaatan TOGA, komunikasi di komunitas dan promosi kesehatan, budidaya dan pengelolaan TOGAdalam rangka peningkatan kesehatan masyarakat, mengenal tanaman obat dengan melihat di kebun Puri Brata serta asuhan mandiri pemanfaatan akupresur disertai praktek.

Materi komunikasi diberikan sebagai dasar agar kader mampu menyampaikan pesan kepada masyarakat. Peran kader adalah sebagai komunikator, menyampaikan pesan dari narasumber, dalam hal ini tenaga kesehatan kepada masyarakat. Pesan bisa berupa masalah kesehatan maupun gagasan baru [8].

Akupresur merupakan hal baru bagi para peserta pelatihan. Materi pelatihan akupresur disampaikan oleh ibu Novika Kurniawati dari Puskesmas Sanden. Para peserta dilatih teknik pemijatan, yaitu ditekan sebanyak 30 kali penekanan sampai terasa ngilu dan dilakukan 1-2 kali sehari. Pemijatan menggunakan jari tangan, telapak tangan, siku atau alat bantu yang berujung tumpul.
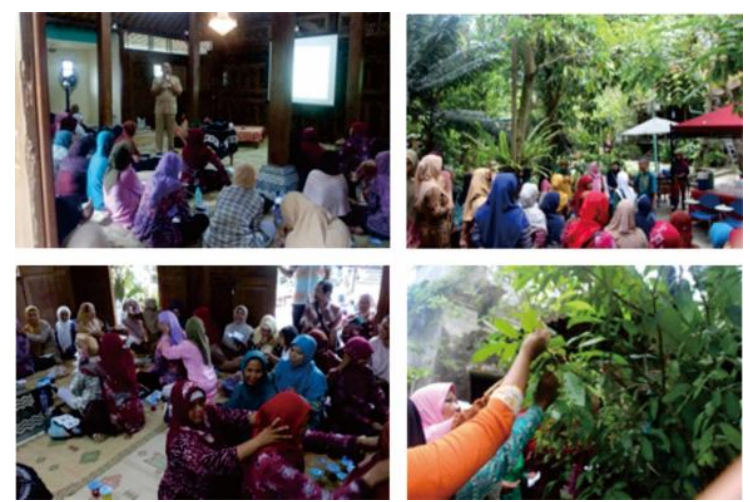

Gambar 2. Suasana pelatihan hari pertama

Acara hari kedua yaitu praktek mengolah jahe dan kunyit menjadi minuman instan.Jahe dan kunyit dipilih untuk kegiatan praktek dengan pertimbangan kedua jenis tanaman tersebut mudah tumbuh, serta bibit telah tumbuh dengan baik dan siap panen. Materi disampaikan oleh bapak Sriyono, praktisi Penyehat Tradisional dari Kasihan Bantul.Topiknya adalah pengantar tentang manfaat kunyit dan jahe, persiapan alat, dilanjutkan dengan mempraktekkan pembuatan jahe dan kunyit instan.Peserta dibagi dalam kelompok kecil, masing-masing kelompok mengerjakan kedua macam minuman instan tersebut.
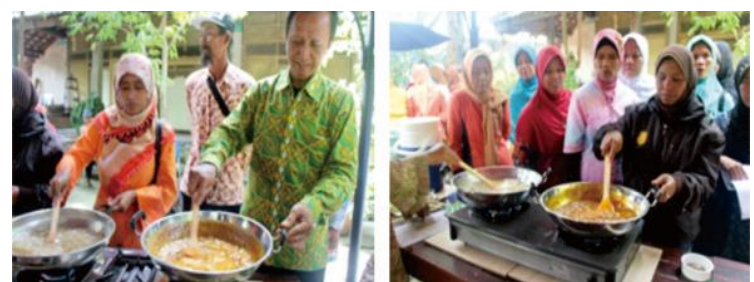

Gambar 3. Praktek membuat jahe dan kunyit instan

Setelah kegiatan pelatihan ini masingmasing peserta mempraktekkan hasil pelatihan antara lain dengan memanfaatkan TOGA dan akupresur untuk mengatasi 
kesehatan ringan, dimulai dari keluarga kemudian di sampaikan kepada warga sekitar.Kegiatan membuat jahe atau kunyit instan pada masing-masing kelompok dilakukan secara rutin. Hasilnya disajikan sebagai minuman pada saat ada acara pertemuan di dusun, seperti rapat RT, kerjabakti maupun acara di desa dan kecamatan.Masing-masing kelompokakan membuat sampel Taman Obat Keluarga yang bisa dimanfaatkan oleh warga, baik sebagai anggota kelompok maupun warga yang bukan anggota.

\section{Studi wisata di Merapi Herbal Farma Kaliurang}

Studi wisata bagi kader dan anggota kelompok asuhan mandiri ke Merapi Herbal Farma bertujuan untuk melihat secara langsung kebun TOGA yang sudah dikelola secara professional. Para peserta studi wisata juga mendengarkan paparan dari pengurus Merapi Herbal Farma tentang potensi daya jual TOGA. Peserta juga mempraktekkan pembuatan minuman beras kencur.

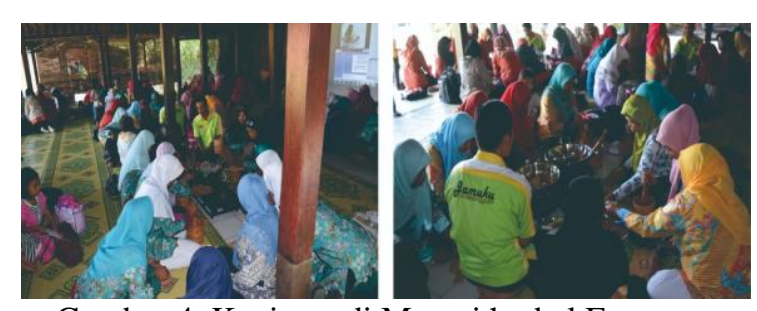

Gambar 4. Kegiatan di Merapi herbal Farma

D. Kegiatan Pengembangan Pembuatan Kebun Toga Bersama di Dusun Kalimundu dan Dusun Piring I

Pembuatan Percontohan KebunToga Bersama di Dusun Kalimundu dan Dusun PiringI bertujuan untuk menyajikan gambaran kebun TOGA yang lengkap. Kegiatan ini didukung oleh pihak pemerintah desa Gadingharjo dan desa Murtigading Kecamatan Sanden. Kebun berlokasi di tanah kas desa yang telah disepakati.Kegiatan diawali dengan kerja bakti persiapan lahan yang dilakukan bersama-sama oleh warga dan pamong, dilanjutkan dengan penanaman TOGA. Bibit TOGA diusahakan secara mandiri oleh anggota kelompok. Untuk melengkapi dibantu oleh FK UKDW. Pemeliharaan dilakukan bersama-sama oleh kelompok asuhan mandiri dengan sistem piket bergantian. Warga yang memerlukan bibit TOGA bisa mendapatkannya disini dengan harga sukarela. Hasil penjualan digunakan untuk pengembangan kebun TOGA tersebut.

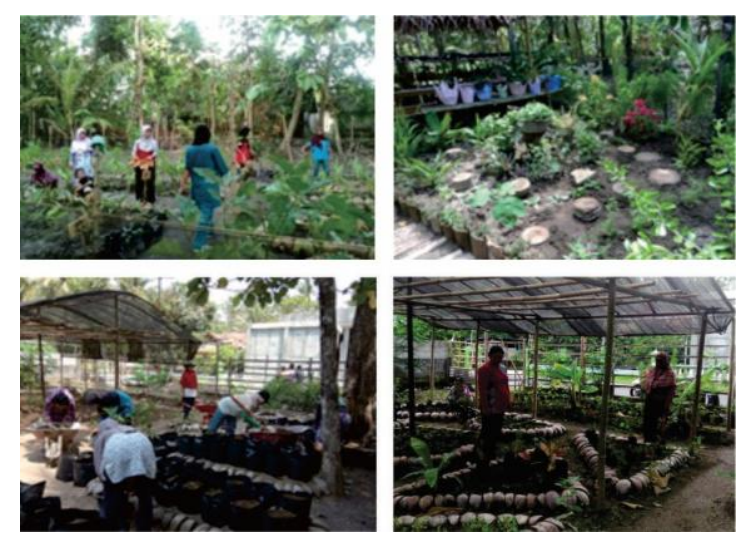

Gambar 5. Kerjabakti pembuatan Taman

Toga Kalimundu dan Taman Toga yang sudah jadi (atas). Bawah: Taman TOGA Piring

\section{E. Monitoring dan evaluasi}

Evaluasi kegiatan dilakukan dengan membandingkan rencana kegiatan dengan realisasi pelaksanaan kegiatan yang telah dilakukan. Hasil evaluasi ini ditampilkan pada laporan kegiatan yang dibuat setelah kegiatan dilaksanakan dan dilaporkan kepada Puskesmas dan FK UKDW sebagai pembina.Kegiatan berjalan dengan baik. Para kader cukup aktif, ada jadwal piket pemeliharaan tanaman di Taman TOGA yang dilakukan secara bergantian setiap hari. Sampai saat ini baru dusun Kalimundu dan Piring yang sudah membuat taman TOGA dusun, sedangkan dusun Dayu dan Gedongan sedang dalam proses persiapan. 
Pada berbagai acara, seperti kerjabakti, rapat RT, pertemuan-pertemuan di dusun, mereka menyajikan jamu sebagai minuman utama. Disamping itu, beberapa keluarga sudah memproduksi jamu instan maupun jamu segar. Pemasaran produk-produk ini dilakukan di berbagai acara, seperti pameran pembangunan, warung sekolah maupun koperasi desa. Ada juga pelanggan tetap yang memesan minuman beras kencur setiap hari sebanyak kira-kira 20 liter per pesanan. Para kader sudah mengikuti pelatihan dan mendapat sertifikat dari Dinas Kesehatan Kabupaten Bantul. Produksi mereka sudah terdaftar PIRT.Kenaikan penghasilan keluarga sudah mulai dirasakan oleh para keluarga yang tergabung dalam kelompok-kelompok ini.

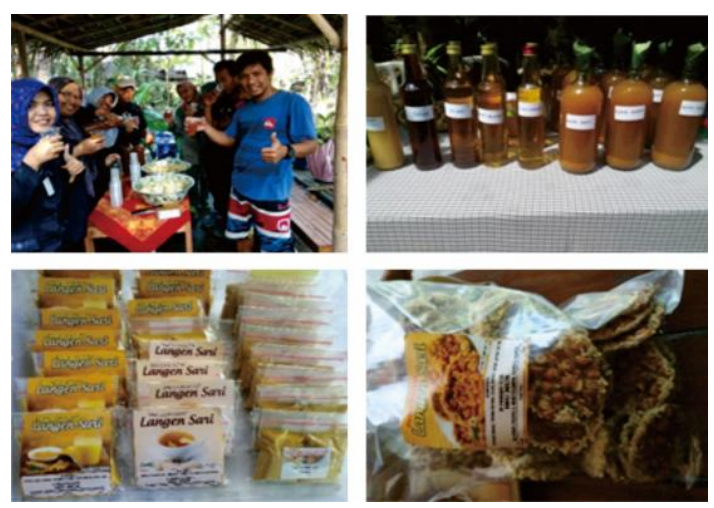

Gambar 6. Berbagai produk olahan TOGA produksi kelompok asuhan mandiri

\section{DISKUSI}

Dasar dari kegiatan pengembangan TOGA adalah Amanah UU No. 36 tahun 2009 tentang Obat tradisional [9]. Pasal 48 menyebutkan bahwa Pelayanan kesehatan tradisional merupakan bagian dari penyelenggaraan upaya kesehatan, yang berarti pengobatan tradisional merupakan bagian dari upaya kesehatan juga. Tujuan lain dari penanaman TOGA adalah pelestarian tanaman yang berkhasiat dan aman digunakan. Hal ini tercantum pada Pasal 101, yaitu sumber obat tradisional yang sudah terbukti berkhasiat dan aman digunakan dalam pencegahan, pengobatan, perawatan, dan atau pemeliharaan kesehatan, tetap dijaga kelestariannya. Dengan menanam TOGA, secara tidak langsung, masyarakat ikut menjaga kelestarian tanaman obat yang berkhasiat.

Lebih spesifik, kelompok asuhan mandiri TOGA dan akupresur tercantum pada Permenkes no 9 tahun 2016tentang Upaya pengembangan kesehatan tradisional melalui asuhan mandiri pemanfaatan TOGA dan akupresur[10]. Pembentukan asuhan mandiri pemanfaatan TOGA dan akupresur merupakan salah satu strategi pembangunan kesehatan, yaitu mendorong masyarakat agar mampu memenuhi kebutuhan hidup sehatnya, serta mengatasi gangguan kesehatan ringan secara mandiri. Adanya peran serta masyarakat secara langsung dalam menjaga kesehatan diri dan lingkungannya menjadikan pelayanan kesehatan semakin luas jangkauannya. Perlu adanya penyegaran pelatihan bagi para kader kesehatan supaya mereka dapat mengakses perkembangan ilmu dan teknologi. Demikian pula perlu dipikirkan inivasi produk TOGA agar semakin bervariasi dan semakin banyak macamnya.

\section{KESIMPULAN}

Pembentukan kelompok asuhan mandiri pemanfaatan TOGA dan akupresur mendorong masyarakat memenuhi kebutuhan hidup sehat dan meningkatkan ekonomi keluarga.

\section{UCAPAN TERIMA KASIH}

Ucapan terimakasih disampaikan kepada Fakultas Kedokteran Universitas Kristen Duta Wacana, Dinas Kesehatan Kabupaten Bantul dan Puskesmas Sanden Bantul. 
[1] Undang Nomor 17 Tahun 2007 tentang Rencana Pembangunan Jangka Panjang Nasional (RPJPN Tahun 2005 - 2025.

[2] Peraturan Pemerintah Nomor 103 tahun 2014 tentang Pelayanan Kesehatan Tradisional

[3] A. Suparmi dan Wulandari, Herbal Nusantara: 1001 Ramuan Tradisional Asli Indonesia, Yogyakarta: Rapha Publisher, 2012.

[4] A. Fengge, Terapi Akupresur Manfaat dan Teknik Pengobatan., Yogyakarta: Circle Corp, 2012.

[5] R. I. W. Hartono, Akupresur Untuk Berbagai Penyakit, Yogyakarta: Rapha Publishing, 2012.
[6] Pedoman Kader Pemanfaatan Tanaman Obat Untuk Kesehatan Keluarga, Jakarta: Kementrian Kesehatan, 2012.

[7] M. d. Slameto, Teknologi Budidaya Jahe, Bandar Lampung: Balai Besar Pengkajian dan Pengembangan Teknologi pertanian Badan Penelitian dan Pengembangan Pertanian, 2008.

[8] D. DS, "Peran komunikator kader posyandu dalam meningkatkan status gizi balita di posyandu Nuri kelurahan Makroma kecamatan Sambutan kota Samarinda," ejournal Ilmu Komunikasi, vol. 5, no. 1, pp. 272-282, 2017.

[9] K. K. R. Indonesia, UU No. 36 tahun 2009 tentang Obat tradisional, Jakarta, 2009.

[10] K. K. R. Indonesia, Permenkes no 9 tahun 2016 tentang Upaya pengembangan kesehatan tradisional melalui asuhan mandiri pemanfaatan TOGA dan akupresur, Jakarta, 2016. 